\title{
Popular diets: why so popular?
}

\author{
Jarl S. Torgerson
}

Department of Medicine, Northern Alvsborg Hospital, Trollhättan, Sweden

Abstract

Obesity is a chronic, prevalent and disabling disorder. Unfortunately, conventional non-surgical treatment programmes are often perceived as less efficient. This creates a vacuum-like situation to be filled by anything that could offer some kind of hope to the afflicted. However, scientific data supporting popular diets are generally scarce or even lacking.

\section{Introduction}

Each year the obesity field faces a lot of new popular diets or other popular treatment strategies, often with substantial commercial success and corresponding media coverage. This is a situation seldom faced in, for instance, the fields of hypertension or appendicitis. Why is this so?

\section{Medical core facts}

Obesity is a chronic and prevalent disorder associated with an increased mortality and morbidity, as well as a reduced health-related quality of life (HRQL). The number of obese individuals is rapidly increasing all over the world and there are basically no age, social or ethnic groups that are not afflicted by the current epidemic. Obese people suffer increased total mortality, as well as increased mortality and morbidity from specific related disorders such as cardiovascular disease, type 2 diabetes and cancer. Furthermore, obesity is disabling from a psychosocial point of view and patients with severe obesity report their HRQL to be at least as low as patients with generalized malignant melanoma (1).

Overweight and obesity are by definition the consequences of a long-standing positive energy balance, i.e. an energy intake that is greater than the energy expenditure. Obesity is also a disorder with both genetic and environmental components and one could argue that "nature loads the gun, while the environment pulls the trigger."

\section{Clinical core facts}

Although there are exceptions, the clinical experience of obesity treatment is not very encouraging. Long-term weight loss, which is important in a chronic condition, is difficult to achieve with conventional, non-surgical treatment programmes. The only approach capable of producing long-term substantial weight loss seems to be bariatric surgery $(2,3)$.

Whereas operated patients can maintain a greater than $15 \%$ weight loss 10 years after bariatric surgery, patients treated with a combined drug and lifestyle approach lose in the order of $5-10 \%$ after 2-4 years of active treatment $(2,4,5)$. Data beyond 4 years are not available from controlled clinical drug trials. However, these smaller weight losses achieved by non-surgical treatment strategies definitely have beneficial effects on cardiovascular risk factors, e.g. a reduced risk of developing type 2 diabetes in patients with impaired glucose tolerance (6).

Unfortunately, obese patients do not receive the attention they deserve from the medical profession; at least this was the case until a few years ago, but since the launch of new antiobesity drugs there seems to be increasing awareness and interest among both doctors and politicians.

\section{Scientific core facts}

Obesity is a chronic disorder and it is thus frustrating that the vast majority of clinical trials are short term ( $<2$ years). Although conventional, nonsurgical treatment can result in a $5-10 \%$ weight loss after 2-4 years of treatment, the high dropout rate is a notorious dilemma (3). Furthermore, almost all trials have so far had weight loss as the primary endpoint, while there are very few clinical trials with mortality or morbidity as hard endpoints. 


\section{So what?}

In conclusion, obesity is a prevalent, chronic and disabling disorder where conventional treatment programmes are not efficient. Such treatment is also associated with a far too high dropout rate. On top of this, the health-care system has not so far paid enough attention to the obese, while the scientific community has focused too much on weight loss and too little on the hard endpoints associated with obesity. In a way, this creates a vacuum-like situation to be filled by anything that could offer some kind of hope to the afflicted. In this context popular diets become very popular.

It is important to keep in mind that popular or alternative treatments should not a priori be condemned. Instead they should stand a fair, evidencebased trial. The Swedish Council on Technology Assessment in Health Care (Swedish abbreviation SBU) has recently shown that the vast majority of obesity treatment strategies that could be classified as alternative medicine (e.g. chromium, aromatherapy, ginger, hypnosis) do not fulfil evidence-based medicine criteria. Consequently, firm conclusions on efficacy and safety cannot be drawn (7).

For some popular diets (low-carbohydrate, highprotein diets, e.g. the Atkins diet), however, there are data showing weight loss and improved cardiovascular risk factors in a short-term perspective and to the same extent as with conventional low-fat diets $(8,9)$. When it comes to diets focusing on low glycaemic index (low-GI) foods there is really no scientific evidence of a weight-reducing effect in humans (10). The same holds true for the palaeolithic diet. Although this dietary approach is embedded in the much broader and interesting framework of evolutionary medicine there are, as yet, no data from prospective clinical trials indicating weight loss or reduced cardiovascular risk $(11,12)$.

\section{What should be done?}

Given the relative lack of efficient, long-term, nonsurgical obesity treatment programmes, is it really so strange that obese individuals turn to popular or alternative diets and treatments? No, it is not - and they should not be blamed for it. Instead of criticizing obese people, the focus should be on clinical research and especially long-term trials, including the investigation of new ideas from alternative medicine. Informing the public about treatment programmes that are really efficient as well as, when needed, fighting commercial and mass media fraud and disinformation is another highly important mission.

\section{References}

1. World Health Organization. Obesity: preventing and managing the global epidemic. Report of a WHO consultation on obesity. WHO Technical Report Series 894. Geneva: WHO; 2000.

2. Sjöström L, Lindroos AK, Peltonen M, Torgerson J, Bouchard C, Carlsson B, et al. Lifestyle, diabetes, and cardiovascular risk factors 10 years after bariatric surgery. N Engl J Med 2004; 351: 2683-93.

3. Solomon CG, Dluhy RG. Bariatric surgery - quick fix or long-term solution? N Engl J Med 2004; 351: 2751-3.

4. Torgerson JS, Hauptman J, Boldrin MN, Sjöström L. XENDOS: a randomized study of Orlistat as an adjunct to lifestyle changes for the prevention of type 2 diabetes in obese patients. Diabetes Care 2004; 27: 155-61.

5. James WPT, Astrup A, Finer N, Hilsted J, Kopelman P, Rössner S, et al. Effect of sibutramine on weight maintenance after weight loss: a randomised trial. Lancet 2000; 356: 2119-25.

6. Torgerson JS. Preventing diabetes in the obese. the XENDOS study and its context. Br J Diabetes Vasc Dis 2004; 4: 22-7.

7. Östman J, Britton M, Jonsson E, eds. Swedish Council on Technology Assessment in Health Care. Treating and preventing obesity. An evidence based review. Weinheim: Wiley-VCH; 2004.

8. Torgerson JS. Low-carbohydrate dieting, what's going on? Scand J Nutr 2003; 47: 167-9.

9. Astrup A, Meinert Larsen T, Harper A. Atkins and other low-carbohydrate diets: hoax or an effective tool for weight loss? Lancet 2004; 364: 897-9.

10. Lindroos AK, Torgerson JS. Obesity treatment: an overview with a dietary perspective. Scand J Nutr 2001; 45: 2-7.

11. Nesse RM, Williams GC. Evolution and healing. The new science of Darwinian medicine. London; Phoenix; 1996.

12. Staffan Lindeberg. Maten och folksjukdomarna - ett evolutionsmedicinskt perspektiv. Lund: Studentlitteratur; 2003.

\footnotetext{
Jarl S Torgerson

Department of Medicine

Northern Älvsborg Hospital

SE-46I 85 Trollhättan

Sweden

E-mail: jarl.torgerson@vgregion.se
} 